\title{
ON PHONON DISPERSION IN ALKALI METALS
}

\author{
P.N. GajJar, B.Y. Thakore, H.K. Patel and A.R. Jani \\ Department of Physics, Sardar Patel University \\ Vallabh Vidyanagar 388 120, Gujarat, India
}

(Received December 30, 1994; revised version May 12, 1995)

\begin{abstract}
In the present paper, the calculation of the phonon dispersion relations for alkali metals to second order in a local pseudopotential is discussed in terms of the real-space sum. Different forms of dielectric functions are employed to judge the varying effects of exchange and correlation on the phonon frequencies. The quantitative agreement of phonon frequencies for the alkali metals reflects, satisfactorily, the expcrimental trend.
\end{abstract}

PACS numbers: 63.20.Dj, 71.25.Cx

\section{Introduction}

Lattice dynamics is one of the fundamental problems in solid state physics and the study of phonon dispersion curves (PDC) offers a primary step towards solving such problems. The development of the pseudopotential theory into a practical computational tool has made tremendous impact in such studies [1]. Grimvall [2] had noted that the theoretical understanding of PDC of $\mathrm{Na}$ is very good, for $\mathrm{Li}, \mathrm{K}$ and $\mathrm{Rb}$ it is good and that for Cs is poor or fair. Mishra and Singh [3] had pointed out that the theoretical studies of PDC of alkali metals based on pseudopotential theory have not succeeded in ascertaining whether the nature and range of interatomic forces vary from one alkali metal to another. Over the past few years, PDC of alkali metals have been investigated on the basis of a variety of model pseudopotentials [3-10, 12-56]. But there have been limited attempts to calculate the PDC of all the five alkali metals ( $\mathrm{Li}, \mathrm{Na}, \mathrm{K}, \mathrm{Rb}$ and $\mathrm{Cs}$ ) by using the same form of the local pseudopotential [4-10]. In these attempts, Ho [4] had used the screened potential formed by linear screening of Heine-Abarenkov type ion potential, and modified Hartree dielectric function to include approximately exchange and correlation effects. The model parameters were determined according to the experimental elastic constants. Price et al. [5] had studied phonon dispersion relations (PDR) of all the five alkali metals with the Aschroft form of the pseudopotential, in which the only parameter is the core radius. The effect of the Coulomb interaction, RPA dielectric function, Hubbard's modified dielectric function and self-consistent dielectric function were also examined in their 
work. Gurskii and Krasko [6] had applied two-parametric local pseudopotential. The parameters were determined using the equation of state of the crystal. Soma [7] had generated PDC of alkali metals using Heine-Abarenkov model. The effect of various forms of exchange and correlation on the phonon frequencies as well as the crossing of dispersion curves in [001] directions were also studied in his investigation. The compression effect on the PDC of $\mathrm{Li}, \mathrm{Na}, \mathrm{K}, \mathrm{Rb}$ and $\mathrm{Cs}$ were also studied by Soma et al. [8]. Sen et al. [9] had obtained PDC of alkali metals using Heine-Abarenkov model in conjunction with Taylor's dielectric function and taken care of the consistency condition. Singh et al. [10] used the exponentially damped two-body interaction obtained in second order perturbation theory with the rational and Lindhard-Taylor dielectric functions along with the Heine-Abarenkov model potential to calculate the phonon spectra of alkali metals. The experimental phonon frequencies of $\mathrm{Cs}$ have been available after the work of Mizuki and Stassis [11]. This might be the reason that in the study of PDR of alkali metals IIafner [12], Sen and Sarkar [13], Sen et al. [14], Das et al. [15] had attended Li, Na, K, $\mathrm{Rb}$ and excluded Cs.

Keeping in mind all the above studies [3-10,12-56], we thought it worthwhile to apply our single parametric local pseudopotential [57] to study the PDR of all the five alkali metals to confirm the applicability and usefulness of our model to light as well as heavy alkali metals. Irence the motivation of the present work comes from the fact that it is desirable to yield satisfactory PDR at primary stage by a physically meaningful pseudopotential before making a comprehensive lattice dynamical calculations.

The dynamical matrix from which phonon energies are calculated may be obtained either by summing real-space force constants or by performing a sum in reciprocal-space. In the present paper the calculation of the phonon frequencies of alkali metals to second order using a local pseudopotential [57] is discussed in terms of the real-space sum. This method is found to converge faster than the more common reciprocal-space sum and to be more convenient for the calculation of smooth dispersion curves $[10,58,59]$. More commonly used dielectric functions, viz. IIartree [60], IIubbard-Sham [61], Kleinman-Lengreth [62], Shaw [63], Vashishta-Singwi [64], and Taylor [65] are employed to judge the relative effects of exchange and correlation in the different branches of the PDC of alkali metals. Finally, the best values of phonon frequencies resulting with a particular dielectric function are selected for the detailed study.

\section{Outline of calculations}

The phonon frequencies can be obtained from the three solutions of the secular determinantal equation [59]

$$
\operatorname{det}\left|D_{\alpha \beta}(q)-4 \pi^{2} \nu^{2} M \delta_{\alpha \beta}\right|=0
$$

where $M$ is the ionic mass, $\nu$ - the phonon frequency and $q$ - the wave vector.

The dynamical matrix, in which the force between two ions depends only upon the distance between them is then given by [58]:

$$
D_{\alpha \beta}(\boldsymbol{q})=\left.\sum_{l}\left(1-\mathrm{e}^{-\mathrm{i} \boldsymbol{q} \cdot \boldsymbol{r}_{1}}\right) \frac{\mathrm{d}^{2} V(r)}{\mathrm{d} r_{l \alpha} \mathrm{d} r_{l \beta}}\right|_{r=r_{l}},
$$


where $r_{l \alpha}$ and $r_{l \beta}$ are the $\alpha$-th and $\beta$-th Cartesian component of the position vector of the $l$-th ion, respectively.

The real-space sum for $D_{\alpha \beta}(q)$ is obtained by defining radial $\left(R_{l}\right)$ and tangential $\left(\tau_{l}\right)$ force constants, which depend only upon the distance between the ions, as $[58,59]$

$$
\tau_{l}=\left.r^{-1} \frac{\mathrm{d} V(r)}{\mathrm{d} r}\right|_{r_{l}}=-\frac{Z^{2} e^{2}}{r_{l}^{3}}-\frac{2 Z^{2} e^{2}}{\pi r_{l}^{2}} \int_{0}^{\infty} C(q)\left(\cos q r_{l}-\frac{\sin q r_{l}}{q r_{l}}\right) \mathrm{d} q
$$

and

$$
R_{l}=\left.\frac{\mathrm{d}^{2} V(r)}{\mathrm{d} r^{2}}\right|_{r_{l}}=-2 \tau_{l}+\frac{2 Z^{2} e^{2}}{\pi r_{l}} \int_{0}^{\infty} C(q) q \sin q r_{l} \mathrm{~d} q
$$

where

$$
C(q)=\left(\frac{q}{4 \pi Z e^{2}}\right)^{2} V_{\mathrm{b}}^{2}(q) \frac{\chi(q)}{[1+1-G(q)] \chi(q)}
$$

and

$$
\chi(q)=\frac{4}{\pi a_{0} k_{\mathrm{F}}} \frac{1}{y^{2}}\left(\frac{1}{2}+\frac{4-y^{2}}{8 y} \ln \left|\frac{2+y}{2-y}\right|\right) .
$$

IIere $y=q / k_{\mathrm{F}}, a_{0}$ is the Bohr radius, $V_{\mathrm{b}}(q)$ - the bare-ion model potential and the function $G(q)$ incorporates exchange and correlation effects among conduction electrons.

Finally, the dynamical matrix element used in the computation is written as

$$
D_{\alpha \beta}(q)=\sum_{l}\left(1-\mathrm{e}^{\mathrm{i} \boldsymbol{q} \cdot \boldsymbol{r}}\right)\left[\tau_{l} \delta_{\alpha \beta}+\left(\frac{r_{l \alpha} r_{l \beta}}{r^{2}}\right)\left(R_{l}-\tau_{l}\right)\right] .
$$

\section{Model potential}

The bare-ion local pseudopotential used in the present calculations is of the form [57] (Rydberg units)

$$
V_{\mathrm{b}}(r)= \begin{cases}-\left(2 Z r / r_{\mathrm{c}}^{2}\right) \exp \left[-\left(r-r_{\mathrm{c}}\right) / r_{\mathrm{c}}\right], & r<r_{\mathrm{c}}, \\ -2 Z / r, & r \geq r_{\mathrm{c}} .\end{cases}
$$

It may be noted that the above form of the potential contains only single parameter $r_{\mathrm{c}}$. This potential is continuous at $r=r_{\mathrm{c}}$ and gets weaker and weaker within the core region. The Fourier transform of the potential in the momentum space turns out to be

$$
\begin{gathered}
V_{\mathrm{b}}(q)=-\frac{8 \pi Z}{\Omega_{0} q^{2}}\left\{\cos x-\frac{1}{\left(1+x^{2}\right)^{3}}\left[\left(5 x-4 x^{3}-x^{5}\right) \sin x\right.\right. \\
\left.\left.+\left(11 x^{2}+4 x^{4}+x^{6}\right) \cos x+2 e x^{2}\left(x^{2}-3\right)\right]\right\}_{x=q r_{c}},
\end{gathered}
$$

where $Z$ is the valency, $\Omega_{0}$ - the atomic volume, $q$ - the wave vector, $e$ - the base of natural logarithm and $r_{\mathrm{c}}$ - the parameter of the potential. The parameter $r_{\mathrm{c}}$ was estimated from $q=q_{0}$ value as described in our recent publications $[57,66,67]$. At $q_{0}$ the pseudopotential form factor, $V_{\mathrm{b}}(q)$, gives first zero. The first few reciprocal lattice vectors lie close to $q_{0}$, so that the sign and the magnitude of $v(q)$ are very sensitive to the position of $q_{0}$. The phonon frequencies and electronic properties are quite sensitive to the position of $q_{0}$ and to the slope of $v(q)$ at $q_{0}$ as well. 
For example, a slight change in the position of $q_{0}$ is enough to lead to an inversion of the order of $W_{1}$ and $W_{2}$ band energies in aluminium [58]. Therefore instead of fitting the $r_{c}$ with any physical property we have used suitable value of $q_{0}$ [61] for determining the parameter $r_{\mathrm{c}}$. This requires that $v(q)=0$ which gives

$$
r_{\mathrm{c}}=2.77429 / q_{0} \text {. }
$$

TABLE I

Parameters and input data.

\begin{tabular}{|c|c|c|c|c|c|c|c|c|c|}
\hline \multirow[t]{2}{*}{ Metal } & \multirow[t]{2}{*}{$Z$} & \multirow{2}{*}{$\begin{array}{c}\Omega_{0} \\
\text { [a.u.] }\end{array}$} & \multirow{2}{*}{$\begin{array}{c}k_{F} \\
{[\text { a.u. }]}\end{array}$} & \multirow[t]{2}{*}{$q_{0} / 2 k_{F}$} & \multirow{2}{*}{$\begin{array}{c}r_{\mathrm{c}} \\
\text { [a.u. }]\end{array}$} & \multicolumn{2}{|c|}{ VS constants [64] } & \multirow{2}{*}{$\begin{array}{l}\text { Ionic mass } \\
\text { in } 10^{-24} \mathrm{~g}\end{array}$} & \multirow{2}{*}{$\begin{array}{c}T \\
{[\mathrm{~K}]^{*}}\end{array}$} \\
\hline & & & & & & $A$ & $B$ & & \\
\hline $\mathrm{Li}$ & 1 & 144.9 & 0.5890 & 1.13 & 2.0841 & 1.0071 & 0.2986 & 11.608 & 78 \\
\hline $\mathrm{Na}$ & 1 & 254.5 & 0.4883 & 0.98 & 2.8995 & 1.0778 & 0.2855 & 38.453 & 90 \\
\hline $\mathrm{K}$ & 1 & 481.4 & 0.3947 & 0.93 & 3.7786 & 1.1673 & 0.2705 & 65.400 & 9 \\
\hline $\mathrm{Rb}$ & 1 & 587.9 & 0.3693 & 0.94 & 3.9960 & 1.1975 & 0.2657 & 142.960 & 85 \\
\hline Cs & 1 & 745.5 & 0.3413 & 1.07 & 3.7997 & 1.2346 & 0.2601 & 222.307 & 280 \\
\hline
\end{tabular}

*This is the temperature of sample at which phonon frequencies were measured in the experiment of neutron scaltering.

The value of $r_{\mathrm{c}}$ and other pertinent data used in the present study are given in Table I. The parameter of our model potential is determined by the first zero of the pseudopotential and we have no fitting parameter to the observed phonon dispersion curves. It is, therefore, very interesting to study phonon spectra of pure alkali metals.

\section{Results and discussion}

The force constants for the alkali metals $\mathrm{Li}, \mathrm{Na}, \mathrm{K}, \mathrm{Rb}$ and $\mathrm{Cs}$ were calculated by performing the integrals in Eqs. (3) and (4) up to $40 k_{\mathrm{F}}$. This covers all the oscillations of the form factor of the pseudopotential. Therefore, any artificial (fictitious) cut-off of the form factor is avoided in the present study. In order to achieve better accuracy at the smaller values of $q$, the real-space sum of $D(q)$ was performed for 30 nearest neighbours. The radial $\left(R_{l}\right)$ and tangential $\left(\tau_{l}\right)$ force constants calculated for $\mathrm{Li}, \mathrm{Na}, \mathrm{K}, \mathrm{Rb}$, and $\mathrm{Cs}$, and further used in the computation of phonon frequencies, are Labulated in Table II.

In addition to experimental studies [11,68-71] the phonon dispersion in the alkali metals have been the subject of several theoretical discussion also [3-10, 12-56] based on pseudopotential theory. The detailed account about the PDC of bcc alkali metals studied here is as below.

\subsection{Lithium (Li)}

This metal happens to be an interesting choice for the study among the alkali metals. Its experimental phonon dispersion from neutron scattering [68] shows that the transverse branch crosses over the longitudinal branch along [100] direction.

The PDC of $\mathrm{Li}$ due to present calculation along with experimental points [68] are displayed in Fig. 1. Surprisingly in our investigation, we have found that 


\begin{tabular}{|c|c|c|c|c|c|c|c|c|c|c|c|c|c|c|c|c|c|}
\hline \multirow{2}{*}{ 咅 } & So & $F$ & 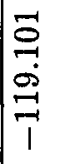 & $\begin{array}{l}8 \\
80 \\
10 \\
1 \\
1\end{array}$ & 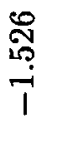 & 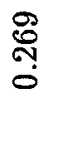 & & $\begin{array}{l}\stackrel{\infty}{3} \\
\stackrel{0}{0}\end{array}$ & & $\begin{array}{l}\stackrel{\infty}{\$} \\
\stackrel{+}{0} \\
0\end{array}$ & $\underset{\stackrel{O}{0}}{\stackrel{O}{0}}$ & $\stackrel{0}{0}$ & & $\stackrel{10}{0}$ & $\stackrel{0}{0}$ & $\begin{array}{l}0 \\
0 \\
0 \\
0 \\
0 \\
1\end{array}$ & 1 \\
\hline & $\begin{array}{l}11 \\
0\end{array}$ & E & 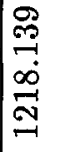 & 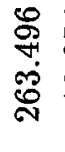 & 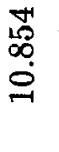 & Fi & 审 & 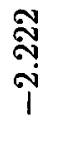 & $\begin{array}{l}R \\
\infty \\
0 \\
0\end{array}$ & 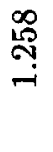 & $\stackrel{0}{\stackrel{0}{0}}$ & 19: & & $\begin{array}{l}\infty \\
\infty \\
0 \\
0\end{array}$ & ڤ્ণ & $\begin{array}{l}\stackrel{15}{S} \\
\stackrel{\operatorname{T}}{0}\end{array}$ & 1 \\
\hline & \multirow{2}{*}{$\begin{array}{l}8 \\
8 \\
8 \\
0 \\
11 \\
0 \\
0\end{array}$} & $F$ & $\frac{0}{\stackrel{0}{r}}$ & \begin{tabular}{l}
$\stackrel{10}{7}$ \\
\multirow{\sigma}{0}{}
\end{tabular} & $\begin{array}{l}\text { 㓠 } \\
\text { is } \\
0 \\
0\end{array}$ & $\underset{\sim}{\overrightarrow{7}}$ & 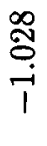 & \begin{tabular}{l}
$\mathbb{0}$ \\
\multirow{0}{0}{}
\end{tabular} & 承 & $\begin{array}{l}-1 \\
\stackrel{8}{0} \\
0\end{array}$ & $\begin{array}{l}\infty \\
\stackrel{8}{0} \\
0 \\
0\end{array}$ & $\stackrel{\circ}{0}$ & & $\stackrel{9}{\circ}$ & $\stackrel{\Rightarrow}{\sigma}$ & $\begin{array}{l}\stackrel{\vartheta}{8} \\
0 \\
\dot{1}\end{array}$ & 1 \\
\hline & & 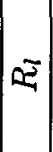 & $\begin{array}{l}\mathscr{\infty} \\
\infty \\
\infty \\
\infty \\
\infty \\
\mathscr{\infty} \\
-1\end{array}$ & 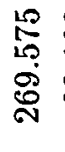 & 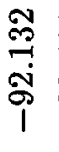 & 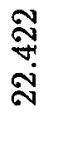 & 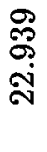 & 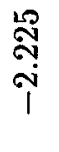 & $\underset{i}{\stackrel{\infty}{+}}$ & 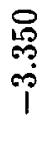 & 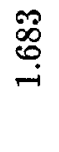 & -1 & & 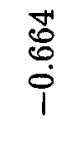 & 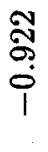 & $\begin{array}{l}\mathbb{C}^{\prime} \\
\infty \\
0 \\
0 \\
1\end{array}$ & 1 \\
\hline \multirow{2}{*}{ 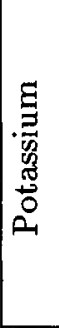 } & \multirow{2}{*}{ 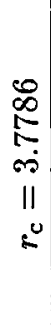 } & $F$ & 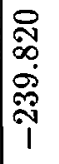 & $\begin{array}{l}\stackrel{0}{-} \\
\underset{-1}{-1} \\
\stackrel{0}{1}\end{array}$ & 冓 & $\begin{array}{l}\stackrel{g}{N} \\
0 \\
0 \\
0\end{array}$ & 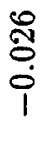 & ث্: & $\begin{array}{l}\stackrel{9}{0} \\
\\
0 \\
\end{array}$ & 占 & $\begin{array}{l}10 \\
0 \\
0 \\
0\end{array}$ & 0 & & $\begin{array}{l}\stackrel{8}{0} \\
\stackrel{10}{0} \\
0\end{array}$ & 용 & ' & 1 \\
\hline & & $\approx$ & $\begin{array}{l}8 \\
\infty \\
\sim \\
\infty \\
\infty \\
\stackrel{N}{\mathbb{N}}\end{array}$ & 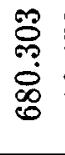 & 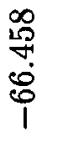 & 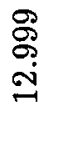 & 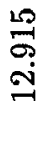 & $\begin{array}{l}\text { is } \\
\text { is } \\
+1 \\
1\end{array}$ & $\underset{i}{\stackrel{N}{+}}$ & $\begin{array}{l}\mathscr{0} \\
\stackrel{0}{10} \\
\text { ஸे } \\
1\end{array}$ & 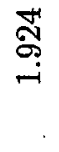 & $\sqrt{5}$ & & $\stackrel{5}{0}$ & $\begin{array}{l}\stackrel{\infty}{\sim} \\
\stackrel{0}{0} \\
\stackrel{\rho}{1}\end{array}$ & 䔬 & 1 \\
\hline \multirow{2}{*}{\begin{tabular}{l}
$\Xi$ \\
$\Xi$ \\
\hdashline
\end{tabular}} & \multirow{2}{*}{$\begin{array}{c}\text { LS } \\
8 \\
\infty \\
\circ \\
11 \\
0 \\
0\end{array}$} & $F$ & 落 & $\begin{array}{l}\infty \\
\stackrel{\infty}{\Rightarrow} \\
\stackrel{\infty}{10}\end{array}$ & $\underset{\stackrel{P}{*}}{\stackrel{P}{+}}$ & $\begin{array}{l}\overrightarrow{0} \\
\stackrel{1}{1}\end{array}$ & $\underset{0}{\stackrel{8}{0}}$ & $\stackrel{\infty}{\stackrel{\infty}{0}}$ & 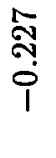 & 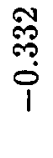 & $\begin{array}{c}\infty \\
\infty \\
1\end{array}$ & $\stackrel{10}{\text { ֻิ }}$ & & 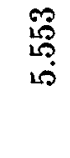 & $\begin{array}{l}8 \\
0 \\
0 \\
0\end{array}$ & ঠُ & 1 \\
\hline & & 2 & 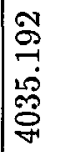 & 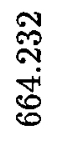 & 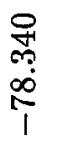 & 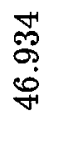 & $\begin{array}{l}\frac{\sigma}{\infty} \\
\infty \\
\infty \\
\infty\end{array}$ & $\begin{array}{l}\stackrel{P}{6} \\
\stackrel{0}{0} \\
\stackrel{0}{1}\end{array}$ & $\begin{array}{l}\infty \\
\underset{+}{+} \\
\dot{j} \\
i\end{array}$ & 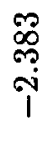 & $\begin{array}{l}\stackrel{0}{\mathscr{P}} \\
\stackrel{9}{*}\end{array}$ & $\stackrel{5}{\sigma}$ & & 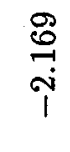 & 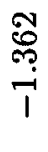 & 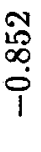 & 1 \\
\hline \multirow{2}{*}{ 丞 } & \multirow{2}{*}{$\begin{array}{c}\overrightarrow{7} \\
0 \\
0 \\
\text { in } \\
11 \\
0 \\
0\end{array}$} & $F$ & $\mid \begin{array}{l}0 \\
0 \\
0 \\
0 \\
8 \\
8 \\
1\end{array}$ & 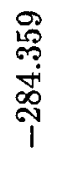 & 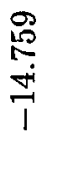 & $\begin{array}{l}\stackrel{g}{9} \\
\stackrel{+}{0}\end{array}$ & $\underset{\stackrel{+}{*}}{\stackrel{\sim}{0}}$ & 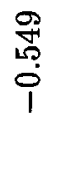 & $\begin{array}{l}\text { 志 } \\
\stackrel{\leftrightarrow}{0}\end{array}$ & $\begin{array}{l}\nabla \\
8 \\
0 \\
0\end{array}$ & 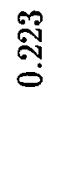 & 0 & & $\underset{\stackrel{O}{0}}{\stackrel{0}{0}}$ & 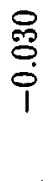 & i & 1 \\
\hline & & F & 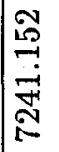 & $\begin{array}{l}\stackrel{8}{S} \\
\infty \\
\dot{8} \\
\stackrel{\leftrightarrow}{\circ}\end{array}$ & $\begin{array}{l}\stackrel{9}{8} \\
\rightarrow \infty \\
\infty \\
\stackrel{\infty}{+}\end{array}$ & 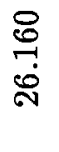 & $\underset{\infty}{\infty}$ & $\begin{array}{l}8 \\
\mathscr{\bullet} \\
\stackrel{1}{1}\end{array}$ & $\begin{array}{l}8 \\
8 \\
0 \\
0\end{array}$ & $\begin{array}{l}10 \\
0 \\
0 \\
0\end{array}$ & $\underset{\dot{1}}{\stackrel{+}{0}}$ & هి & & $\begin{array}{l}\mathbb{N} \\
\stackrel{0}{0}\end{array}$ & $\begin{array}{l}8 \\
0 \\
0 \\
0\end{array}$ & & 1 \\
\hline $\bar{\Xi}$ & 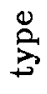 & & $\overparen{\Xi}$ & త్రి & 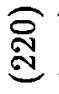 & $\underset{\overparen{B}}{\overparen{B}}$ & ָิ & $\underset{8}{\stackrel{8}{8}}$ & శ્ & 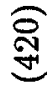 & Ð્す & & & 8 & تี & & \\
\hline$\frac{\bar{d}}{\Delta}$ & $\dot{0}$ & & $-\dot{-i}$ & N & "ه & $\nabla$ & ס & & & & $\dot{\sigma}$ & & & $?$ & & & \\
\hline
\end{tabular}




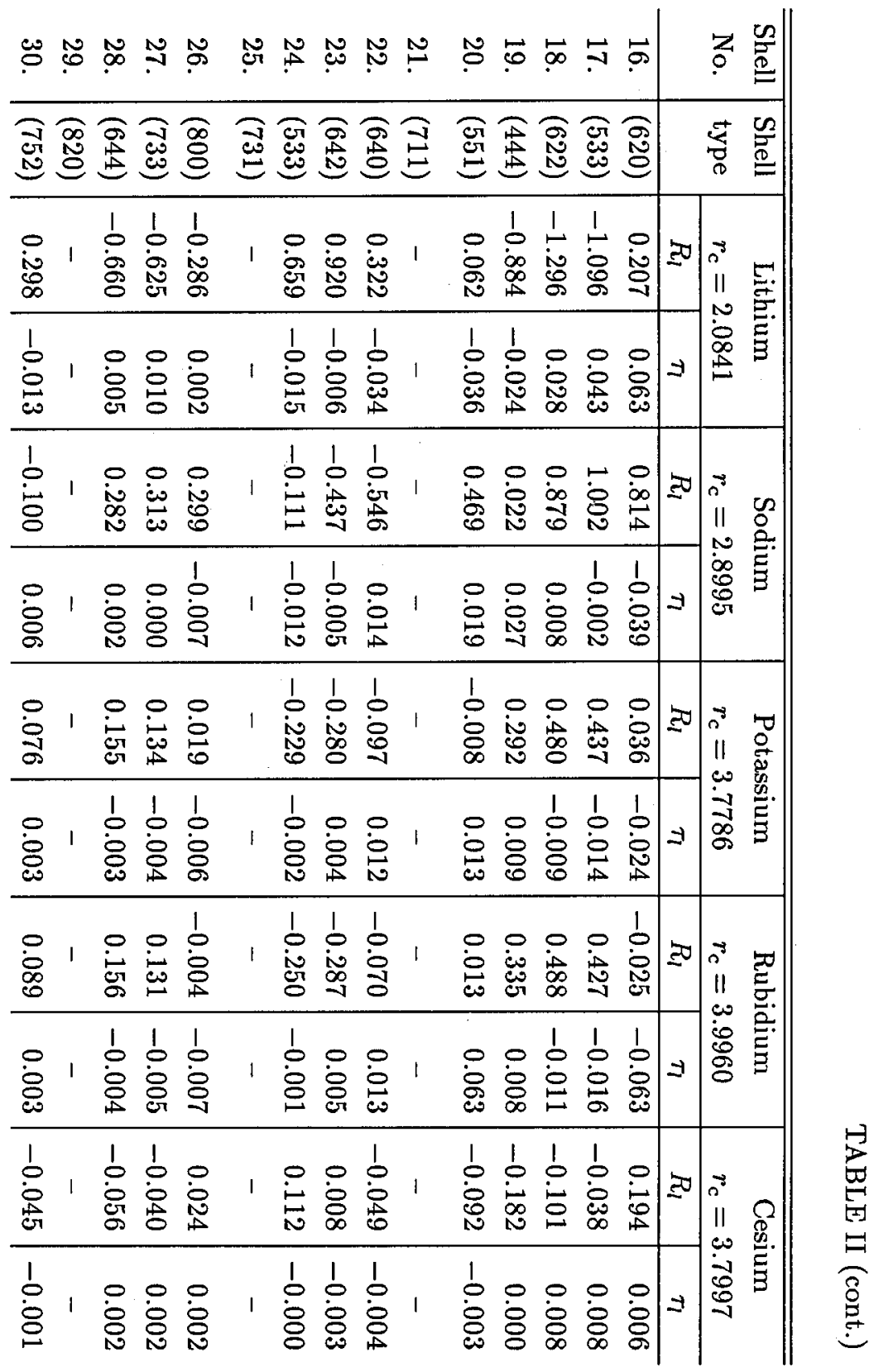

Hartree [60] dielectric function could reproduce the best results among all the six dielectric functions employed here. But we do not claim the exact reproducibility of the cross-over along [100] direction. Because the results with H-screening function [60] show that near zone boundary, the longitudinal and transverse modes are 


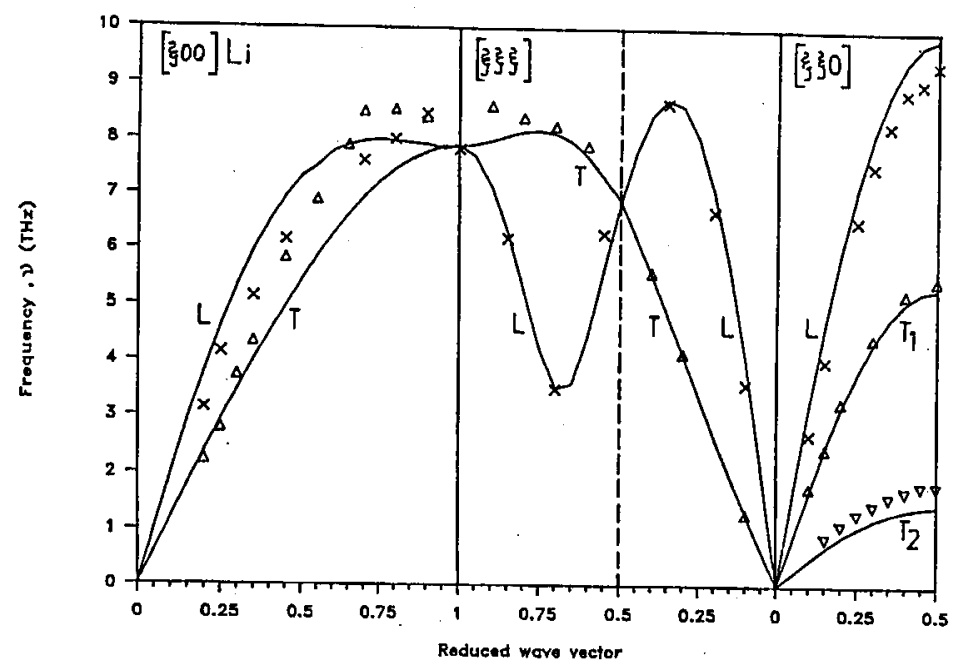

Fig. 1. Phonon dispersion curves of lithium $(\mathrm{Li})$ for the wave numbers along the directions [100], [110] and [111]. Full (solid) line curves represent the results of the present study with H-screening functions. Experimental points depicted by legends $\times, \Delta$ and $\nabla$ are due to Smith et al. [68].

almost degenerate and there is a slight cross-over of both the branches beyond $q=0.9$. With the Taylor [65] screening function, this happens beyond $q=0.85$. When V-S [64] screening function is used it is found that the crossing takes place above $q=0.85$ with a very narrow separation between both the branches beyond $q=0.6$. To get an idea about the exact location of the cross-over in [100], the numerical values of the phonon frequencies are tabulated in Table III. From Fig. 1 and Table III, it seems that the sharpness of the PDC of Li along [100] direction may be due to the exchange and correlation effects. However, overall agreement with experimental findings is quite satisfactory and almost similar to the previously rcported work $[4-35,41,52,54]$.

\subsection{Sodium $(\mathrm{Na})$}

This is metal much favoured by many people for the application of the constructed potential in the calculations of PDR. A good number of satisfactory calculations exists for the phonons propagation along the symmetry directions of metallic sodium [4-17, 22, 24, 30, 35-42, 48, 55, 56]. This is mainly due to the fact that the conduction electrons response to the vibrating ions, through which the pseudopotential enters the calculations, accounts for a relatively small proportion of the effective interaction between ions. Moreover, as band effects are negligible and Fermi surface of $\mathrm{Na}$ is almost spherical, it is easy to establish an exact appropriateness of any pseudopotential at a primary stage.

The calculated phonon frequencies of sodium on the basis of present study are shown in Fig. 2. An overall satisfactory agreement between the theory and experiment [69] can be noticed from the dispersion curves. Here, the Taylor [65] 
TABLE III

Phonon frequencies (in THz) of lithium in [100] direction.

\begin{tabular}{c|c|c|c|c|c|c}
\hline \hline \multirow{2}{*}{$\begin{array}{l}\text { Reduced } \\
\text { wave }\end{array}$ vector } & \multicolumn{3}{|c|}{ Phonon frequencies with different screening functions } \\
\cline { 2 - 7 } & \multicolumn{2}{|c|}{ Hartree [60] } & \multicolumn{2}{|c}{ Taylor [65] } & \multicolumn{2}{c}{ V-S [64] } \\
\cline { 2 - 7 } & $\nu_{\mathrm{L}}$ & $\nu_{\mathrm{T}}$ & $\nu_{\mathrm{L}}$ & $\nu_{\mathrm{T}}$ & $\nu_{\mathrm{L}}$ & $\nu_{\mathrm{T}}$ \\
\hline 0.05 & 0.99 & 0.60 & 0.68 & 0.60 & 0.65 & 0.60 \\
0.10 & 1.98 & 1.20 & 1.35 & 1.18 & 1.28 & 1.20 \\
0.15 & 2.92 & 1.79 & 1.99 & 1.75 & 1.90 & 1.77 \\
0.20 & 3.80 & 2.37 & 2.60 & 2.31 & 2.50 & 2.33 \\
0.25 & 4.61 & 2.93 & 3.15 & 2.83 & 3.05 & 2.87 \\
0.30 & 5.33 & 3.47 & 3.67 & 3.33 & 3.57 & 3.39 \\
0.35 & 5.97 & 3.99 & 4.13 & 3.81 & 4.07 & 3.88 \\
0.40 & 6.51 & 4.50 & 4.56 & 4.26 & 4.53 & 4.35 \\
0.45 & 6.96 & 4.98 & 4.96 & 4.68 & 4.96 & 4.79 \\
0.50 & 7.32 & 5.44 & 5.31 & 5.07 & 5.36 & 5.20 \\
0.55 & 7.59 & 5.87 & 5.62 & 5.42 & 5.72 & 5.58 \\
0.60 & 7.78 & 6.27 & 5.91 & 5.75 & 6.05 & 5.93 \\
0.65 & 7.90 & 6.63 & 6.17 & 6.05 & 6.34 & 6.24 \\
0.70 & 7.97 & 6.95 & 6.40 & 6.31 & 6.60 & 6.52 \\
0.75 & 7.99 & 7.23 & 6.60 & 6.52 & 6.82 & 6.74 \\
0.80 & 7.97 & 7.45 & 6.75 & 6.70 & 6.99 & 6.94 \\
0.85 & 7.94 & 6.64 & 6.87 & 6.86 & 7.12 & 7.10 \\
0.90 & 7.90 & 7.77 & 6.93 & 6.96 & 7.18 & 7.22 \\
0.95 & 7.83 & 7.88 & 6.98 & 7.02 & 7.24 & 7.28 \\
1.00 & 7.88 & 7.87 & 7.02 & 7.03 & 7.30 & 7.30 \\
& & & & &
\end{tabular}

dielectric function has reproduced the best results among all screening functions that we have considered.

\subsection{Potassium (K)}

The trend of PDC of potassium is almost similar to that of sodium and hence people have reported expected results for its phonon frequencies on the basis of different model potentials [4-16, 22, 24, 38, 39, 41, 42, 48-50, 55, 56]. We have also obtained excellent results for PDC of potassium. This can be adjudged from the comparison of our theoretical curves with the experimental points [70], as shown 


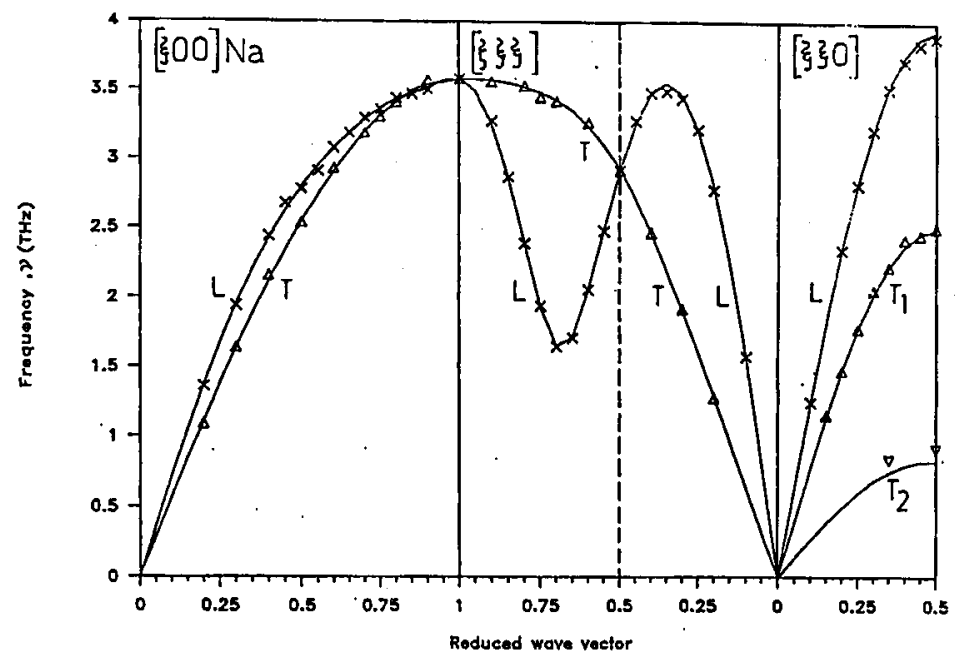

Fig. 2. Phonon dispersion curves of sodium $(\mathrm{Na})$ for the wave numbers along the dircctions [100], [110] and [111]. Full (solid) line curves represent the results of the present study with T-screening functions. Experimental points depicted by legends $\times$, $\Delta$ and $\nabla$ are due to Woods et al. [69].

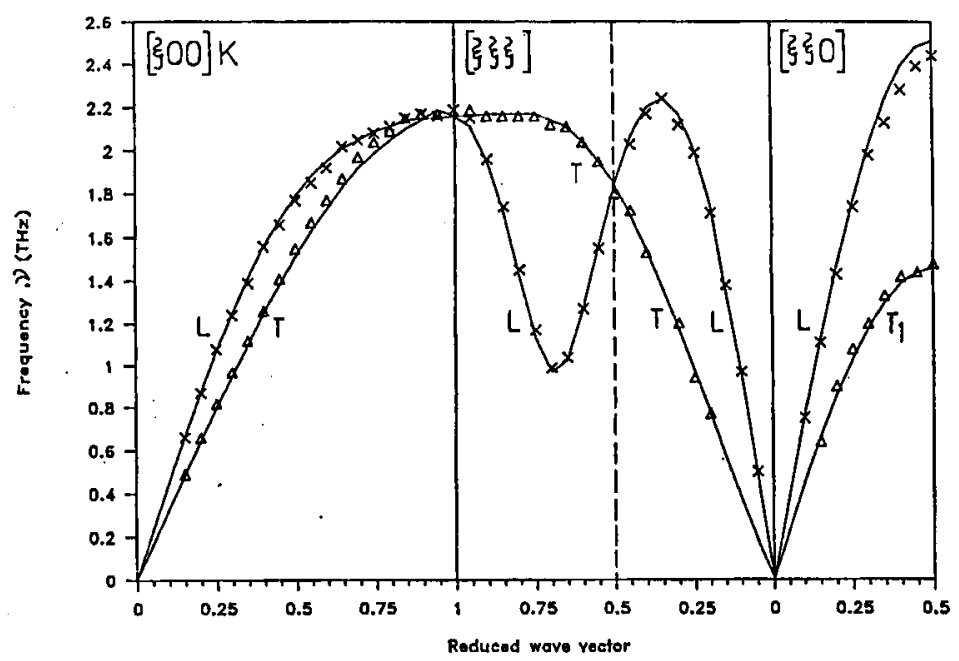

Fig. 3. Phonon dispersion curves of potassium (K) for the wave numbers along the directions [100], [110] and [111]. Full (solid) line curves represent the results of the present study with KL-screening functions. Experimental points depicted by legends $x$, $\triangle$ and $\nabla$ are due to Cowley et al. [70].

in Fig. 3. We further note that in the present study, K-L [62] dielectric function has given the best agreement with experimental values. 


\subsection{Rubidium ( $R b)$}

This metal possesses a large thermal expansivity and hence it provides a good opportunity to study the volume dependence of the phonons in some detail. Due to this feature of $\mathrm{Rb}$, Copley and Brockhouse [71] have reported accurate measurements of the PDR at different temperatures, such as $12 \mathrm{~K}, 85 \mathrm{~K}, 120 \mathrm{~K}$, and $205 \mathrm{~K}$. Here our main efforts are devoted to the study of PDC of Rb along three major symmetry directions. In Fig. 4 the PDC of Rb obtained in the present work are shown along with the experimental points [71]. The agreement between theory and experiment is excellent and the results are compatible to other such findings $[4-16,24,25,41,43-45,51,53]$. For $\mathrm{Rb}$, the use of $\mathrm{V}-\mathrm{S}$ [64] dielectric function has yielded satisfactory results.

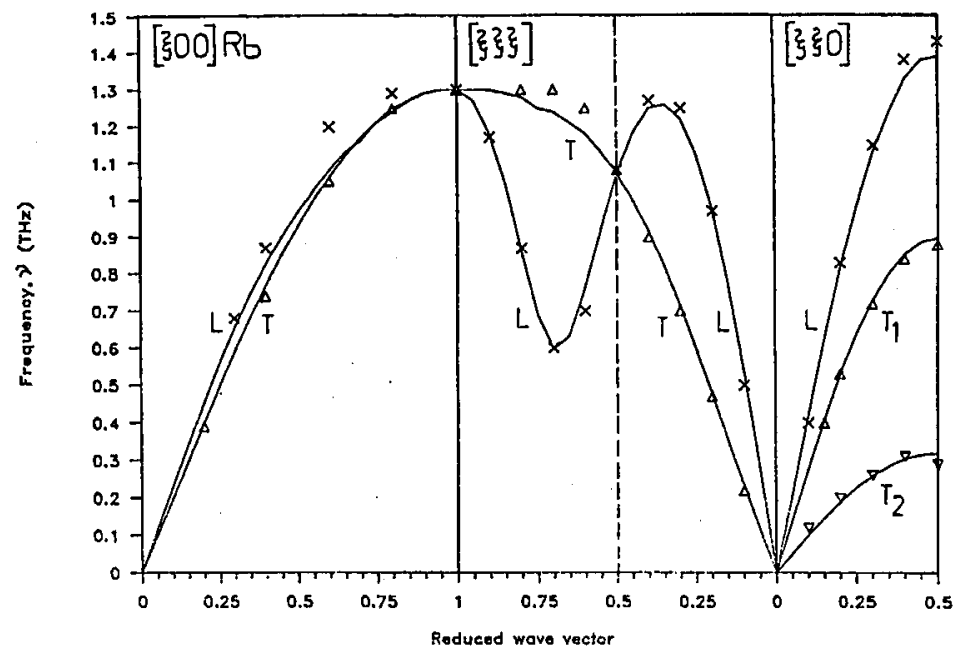

Fig. 4. Phonon dispersion curves of rubidium $(\mathrm{Rb})$ for the wave numbers along the directions [100], [110] and [111]. Full (solid) line curves represent the results of the present study with VS-screening functions. Experimental points depicted by legends $\times$, $\triangle$ and $\nabla$ are due to Copley and Brockhouse et al. [71].

\subsection{Cesium (Cs)}

This is the heaviest among all the alkali metals. Moreover, chemically it is most reactive and hence it is difficult to obtain its sufficiently large sized samples in single crystal form. Due to this reason, people had to attend this metal without experimental data for quite a long time. Mizuki and Stassis [11] have reported in detail the measured values of its phonon frequencies. The comparison between experimental findings [11] and our calculations of dispersion relations, incorporating Hartree [60] dielectric function are shown in Fig. 5. If we look to the previous such studies [4-10, 25, 43,44,45] it is interesting to point out that for Cs Singh et al. [10] have obtained really better PDC. In all the three symmetry directions 


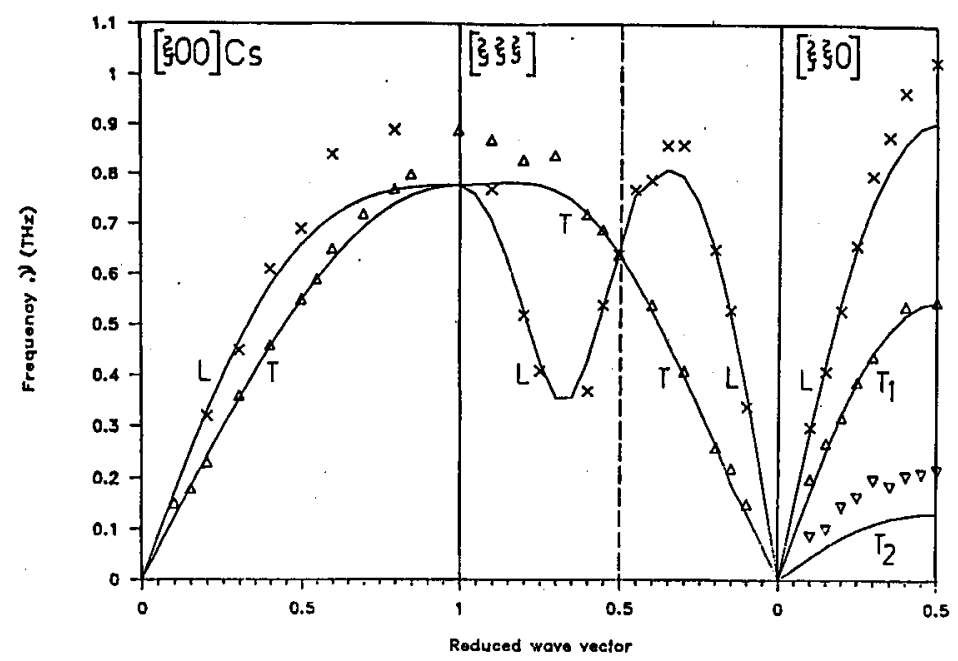

Fig. 5. Phonon dispersion curves of cesium (Cs) for the wave numbers along the directions [100], [110] and [111]. Full (solid) line curves represent the results of the present study with $H$-screening functions. Experimental points depicted by legends $\times, \Delta$ and $\nabla$ are due to Mizuki and Stassis [11].

we could generate good results only for the small values of $q$. For higher values of wave vector our theoretical findings are lower than the experimental points. Any reason could be possible for this discrepancy. As cesium is a heavy alkali metal, probably relativistic effects might be playing an effective role.

\section{Conclusions}

In the present paper, instead of reciprocal-space sum method, we have used real-space sum method to demonstrate that with an appropriate choice of bare-ion pseudopotential and dielectric function, one can achieve an excellent agreement between calculated and experimental phonon frequencies. For this purpose, a local form of the potential bearing only one parameter and commonly used six different dielectric functions are employed. As the parameter of the potential is estimated on a sound physical basis by using $q=q_{0}$ value, the results for the evaluated phonon frequencies for the alkali metals are highly encouraging. Here pseudopotential form factor is characterised without fitting any experimental phonon frequency at zone boundary, therefore, overall good results in all the symmetry directions could indicate the possibility for further investigation of remaining lattice dynamical study in detail. Apart from a cross-over between the longitudinal and transverse branches in the [100] direction of $\mathrm{Li}$ and low lying modes in $\mathrm{Cs}$, excellent agreement between theory and experiment is observed. Just to highlight the results it may be noted that $\nu_{\mathrm{L}}(100)$ frequency of all the alkali metals is found to be in agreement with experimental value within maximum deviation up to $1.37 \%$. Such deviation for the frequency $\nu_{\mathrm{L}}(1 / 2,1 / 2,1 / 2)$ is noticed to be maximum up to $5 \%$. But it is absolutely necessary to examine the stability of the potential against various 
dielectric functions before its application for the comprehensive study of metals. This can give a unique combination of bare-ion pseudopotential with a proper screening function and hence one can also decide the nature of screening in the particular metal. It would be interesting to repeat the present investigation by employing Ichimaru-Utsumi [72] screening function. This function accurately reproduces the Monte Carlo results as well as those of the microscopic calculations and which satisfies the self-consistency conditions in the compressibility sum rule and the short range correlation. Further, we also add here that to examine the fine structure characteristics of PDC, on the basis of pseudopotential theory, one must incorporate the complete character of the form factor as well as sufficient long range forces.

\section{References}

[1] K.R. Rao, Curent Trends in Lallice Dynamics, IPA Publication, Bombay 1978.

[2] G. Grimvall, Ab-initio Calculation of Phonon Spectra, Plenum Publ. Co., New York 1983 , p. 117.

[3] S.K. Mishra, T.N. Singh, Phys. Slatus Solidi B 158, 153 (1990).

[4] P.S. Ho, Phys. Rev. 169, 523 (1968).

[5] D.L. Price, K.S. Singwi, M.P. Joshi, Phys. Rev. B 2, 2983 (1970).

[6] Z.A. Gurskii, G.L. Krasko, Sov. Phys.-Doklady 16, 298 (1971).

[7] T. Soma, Phys. Status Solidi B 99, 195 (1980).

[8] T. Soma, Y. Kimura, H.-M. Kagaya, Phys. Status Solidi B 112, 151 (1982).

[9] D. Sen, S.K. Sarkar, S. Sengupta, D. Roy, Phys. Stalus Solidi B 115, 593 (1983).

[10] N. Singh, N.S. Banger, S.P Singh, Phys. Status Solidi B 148, K-5 (1988); Phys. Status Solidi B 149, 63 (1988); Phys. Rev. B 39, 3097 (1989); Phys. Lett. A 135, 368 (1989).

[11] J. Mizuki, C. Stassis, Phys. Rev. B 34, 5890 (1986).

[12] J. Hafner, Z. Phys. B 24, 41 (1976).

[13] D. Sen, S.K. Sarkar, Phys. Rev. B 22, 1856 (1980).

[14] D. Sen, S.K. Sarkar, S.K. Das, D. Roy, S. Sengupta, Acta Phys. Pol. A 57, 73 (1980).

[15] S.K. Das, D. Roy, S. Sengupta, Acta Phys. Pol. A 59, 775 (1981).

[16] H.C. Gupta, B.B. Tripathi, J. Phys. F 1, 12 (1971); J. Chem. Phys. 54, 435 (1971); Indian J. Pure Appl. Phys. 9, 781 (1971).

[17] C.M. Bertoni, V. Bortolani, C. Calandra, F. Nizzoli, J. Phys. F 4, 19 (1974).

[18] S. Nand, B.B. Tripathi, Phys. Lett. A 54, 217 (1975).

[19] L.F. Magana, G. Vanquez, J. Phys. F 17, L-237 (1987); Phys. Rev. B 36, 4700 (1987).

[20] G.J. Vanquez, L.F. Magana, J. Phys. (France) 49, 497 (1988).

[21] M. Juat, Solid State Commun. 65, 905 (1988).

[22] D.C. Wallace, Phys. Rev. 176, 832 (1968); Phys. Rev. 178, 900 (1969).

[23] V. Bortolani, G. Pizzichini, Phys. Rev. Lett. 22, 840 (1969). 
[24] S. Prakash, S.K. Joshi, Phys. Rev. 187, 808 (1969).

[25] B. Prasad, R.S. Srivastava, Phys. Rev. B 6, 2192 (1972); Phys. Status Solidi B 59, 327 (1973); Phys. Status Solidi $B$ 80, 379 (1977).

[26] C.M. Kachhava, Phys. Status Solidi B 54, K29 (1972).

[27] P.L. Srivastava, N.R. Mitra, N. Mishra, J. Phys. F 3, 1388 (1973).

[28] W.F. King III, P.H. Cutler, Phys. Rev. B 8, 1303 (1973); J. Phys. F 5, L-187 (1975).

[29] S.S. Kushwaha, Phys. Status Solidi B 59, 285 (1973).

[30] P.H. Cutler, R. Day, W.F. King III, J. Phys. F 5, 1801 (1975).

[31] J.P. Perdew, S.V. Vosko, J. Phys. F 6, 1421 (1976).

[32] R.N. Singh, P.L. Srivastava, N.R. Mitra, Phys. Status Solidi B 83, 651 (1977).

[33] Y.R. Wang, A.W. Overhauser, Phys. Rev. B 34, 497 (1986); Phys. Rev. B 35, 501 (1987).

[34] R. Day, F. Sun, P.H. Cutler, W.F. King III, J. Phys. F 6, L-137 (1976); J. Phys. 7, L-169 (1977).

[35] P.S. Ho, A.L. Ruoff, Phys. Status Solidi B 23, 489 (1967).

[36] M.A. Coulthard, J. Phys. C 3, 820 (1970).

[37] L. Martheneth, Nuovo Cimento B 70, 58 (1970).

[38] R.S. Srivastava, K. Singh, Phys. Status Solidi B 39, 25 (1970).

[39] V.K. Jindal, Can. J. Phys. 53, 1507 (1975).

[40] A. Reissland, O. Ese, J. Phys. F 5, 110 (1975).

[41] T. Schneider, E. Stoll, Phys. Condens. Matter 5, 364 (1966); Phys. Condens. Matter

8, 58 (1968); Computational Solid State Physics, Plenum Press, New York 1972, p. 97 .

[42] S.S. Khushava, J.S. Rajput, Phys. Rev. B 2, 3943 (1970).

[43] P.L. Srivastava, N. Mishra, J. Phys. F 2, 1046 (1972).

[44] C.B. So, S. Wang, J. Phys. F 7, 35 (1977).

[45] R. Taylor, A.H. McDonald, J. Phys. F 10, 2387 (1980).

[46] R. Ramamurthy, M. Satishkumar, Physica $B+C$ 111, 297 (1981).

[47] M.S. Chung, P.H. Cutler, F. Sun, Phys. Rev. B 33, 2125 (1986).

[48] E.G. Brovman, Yu. Kagan, A. Kholas, Sov. Phys.-Solid State 12, 786 (1970).

[49] R.S. Day, F. Sun, P.H. Cutler, Phys. Rev. A 19, 328 (1979).

[50] D.J.W. Geldart, R. Taylor, Y.P. Varshni, Can. J. Phys. 48, 183 (1970).

[51] A.R. Jani, V.B. Gohel, Acta Phys. Acad. Sci. Hung. 51, 325 (1981).

[52] D.H. Li, R.A. Moore, S. Wang, J. Phys. F 17, 2007 (1987).

[53] F. Sun, R. Day, P.H. Cutler, Solid State Commun. 27, 835 (1978).

[54] S. Pal, Phys. Rev. B 2, 4741 (1970).

[55] S.K. Srivastava, J. Phys. Chem. Solids 38, 451 (1977).

[56] S.A. Taole, H.R. Glyde, Can. J. Phys. 57, 1870 (1979).

[57] H.K. Patel, A.R. Jani, in: Proc. 4th Asia Pacific Physics Conf., South Korea 1990, Eds. S.H. Ahn, S.H. Choh, Il.T. Cheon, C. Lee, World Scientific Pub. Co., Singapore 1991, p. 432. 
[58] W.H. Hartmann, T.O. Milbrodt, Phys. Rev. B 3, 4133 (1971).

[59] V.B. Gohel, C.K. Acharya, A.R. Jani, J. Phys. F 15, 279 (1985).

[60] W.A. Harrison, Pseudopotentials in the Theory of Metals, W.A. Benjamin, New York 1967.

[61] V. Heine, M.L. Cohen, D. Weaire, Solid State Physics, Academic Press, New York 1970, p. 24.

[62] L. Kleinman, D.C. Langreth, Phys. Rev. 160, 589 (1967); Phys. Rev. 172, 383 (1969).

[63] R.W. Shaw, J. Phys. C 3, 875 (1972).

[64] P. Vashishta, K.S. Singwi, Phys. Rev. B 6, 875 (1972).

[65] R. Taylor, J. Phys. F 8, 169 (1978).

[66] A.R. Jani, P.N. Gajjar, H.K. Patel, Phys. Status Solidi B 169, K105 (1992).

[67] R.S. Avte, P.N. Gajjar, A.R. Jani, Phys. Status Solidi B 176, K59 (1993).

[68] H.G. Smith, G. Dolling, R.M. Nicklow, P.R. Vijayragha van, M.K. Wilkinson, Neutron Inelastic Scattering I, 149 (1968).

[69] A.D.B. Woods, B.N. Brockhouse, R.H. March, A.T. Stewart, R. Bowers, Phys. Rev. 128, $1112(1962)$.

[70] R.A. Cowley, A.D.B. Woods, G. Dolling, Phys. Rev. 150, 487 (1966).

[71] J.R.D. Copley, B.N. Brockhouse, Can. J. Phys. 51, 657 (1973).

[72] S. Ichimaru, K. Utsumi, Phys. Rev. B 24, 7385 (1981). 